\title{
Neurological Manifestations of Myeloneuropathy in Patients with Nitrous Oxide Intoxication
}

\author{
Sung Woo Kang \\ Ji Man Hong \\ Dong Wook Namgung \\ Young-Chul Choi \\ Department of Neurology, \\ Yonsei University College of Medicine, \\ Seoul, Korea
}

Received July 13, 2018

Revised August 1,2018

Accepted August 1,2018

\section{Correspondence}

Young-Chul Choi, $\mathrm{MD}, \mathrm{PhD}$

Department of Neurology,

Yonsei University College of Medicine,

211 Eonju-ro, Gangnam-gu,

Seoul 06273, Korea

Tel +82-2-2019-3323

Fax +82-2-3462-5904

E-mailycchoi@yuhs.ac
Dear Editor,

Nitrous oxide $\left(\mathrm{N}_{2} \mathrm{O}\right)$ is a long-standing anesthetic that also exhibits neurotoxicity by interfering with the bioavailability of vitamin $\mathrm{B}_{12}$. The euphorigenic effects of $\mathrm{N}_{2} \mathrm{O}$ result in it often being abused by adolescents. Various neurological manifestations have been described for the neurotoxicity of $\mathrm{N}_{2} \mathrm{O}$, such as myelopathy, peripheral neuropathy, and subacute combined degeneration. ${ }^{1}$ Psychiatric disorder and medical sequelae also have been reported. ${ }^{2}$

Four patients with progressive limb paralysis after recreationally inhaling $\mathrm{N}_{2} \mathrm{O}$ were admitted to the neuromuscular clinic. All of the patients were women, were aged 21-36 years, had abused $\mathrm{N}_{2} \mathrm{O}$ for between 1 and 5 months, and exhibited some degree of motor weakness in the lower extremities. Sensory examinations revealed paresthesia in three of the four patients. Patient 1 had no sensory deficit and described a tingling sensation, while Patient 3 reported burning pain. Two patients (Patients 2 and 3) had decreased positional and vibration senses, and a positive Romberg's sign. In addition to the neurological deficit, Patient 4 showed psychiatric symptoms such as irritability, agitation, reduced sleep, delusions of references (i.e., thinking that others were doubting her), and anxiety. Patient 4 was also diagnosed with incidental pulmonary thromboembolisms with lung infarctions. Serological tests indicated the absence of anemia in Patients 1,2, and 3, but an increased mean corpuscular volume, while Patient 4 showed moderate anemia with macrocytosis. The vitamin $B_{12}$ level was low and the homocysteine level was high in all patients. Cerebrospinal fluid analysis showed normal protein and cell counts in all patients. In nerve conduction studies, two patients (Patients 1 and 2) presented with demyelinating polyneuropathy, one (Patient 4) with axonal polyneuropathy, and one (Patient 3) without neuropathy. Median and posterior tibial somatosensory evoked potential tests demonstrated central conduction defects in three patients (Patients 1, 2, and 3). Spinal MRI showed high T2-weighted signals in the posterior column in three of the patients (Patients 1, 2, and 3) (Fig. 1). However, Patient 4, who initially had normal spine MRI findings, continued to inhale $\mathrm{N}_{2} \mathrm{O}$ gas, and follow-up MRI showed high T2-weighted signals in the posterior column (Fig. 1I and J).

For treatment, intramuscular vitamin $B_{12}$ was administered to all patients. Patient 1 additionally received intravenous immunoglobulin therapy for 5 days to address the superimposed Guillain-Barré syndrome. Patient 4 received a direct oral anticoagulant (apixaban, $5 \mathrm{mg}$ bid) due to pulmonary thromboembolisms.

Neuropathy induced by $\mathrm{N}_{2} \mathrm{O}$ has various clinical and neurophysiological manifestations. ${ }^{1}$ Some neurophysiological studies of $\mathrm{N}_{2} \mathrm{O}$-induced peripheral neuropathy have predominantly found axonal neuropathy, ${ }^{3}$ while others showed demyelinating neuropathy. ${ }^{4}$ The clinical manifestations in our patients could be classified into two categories: myelopathy with peripheral neuropathy (Patients 1, 2, and 4) and myelopathy without peripheral neuropathy (Patient 3). The neurophysiological studies applied to our patients revealed different patterns: Patients 1 and 2 showed demyelinating-type polyneuropathy, and Patient 4 showed sensory-dominant

@ This is an Open Access article distributed under the terms of the Creative Commons Attribution Non-Commercial License (https://creativecommons.org/licenses/by-nc/4.0) which permits unrestricted non-commercial use, distribution, and reproduction in any medium, provided the original work is properly cited. 

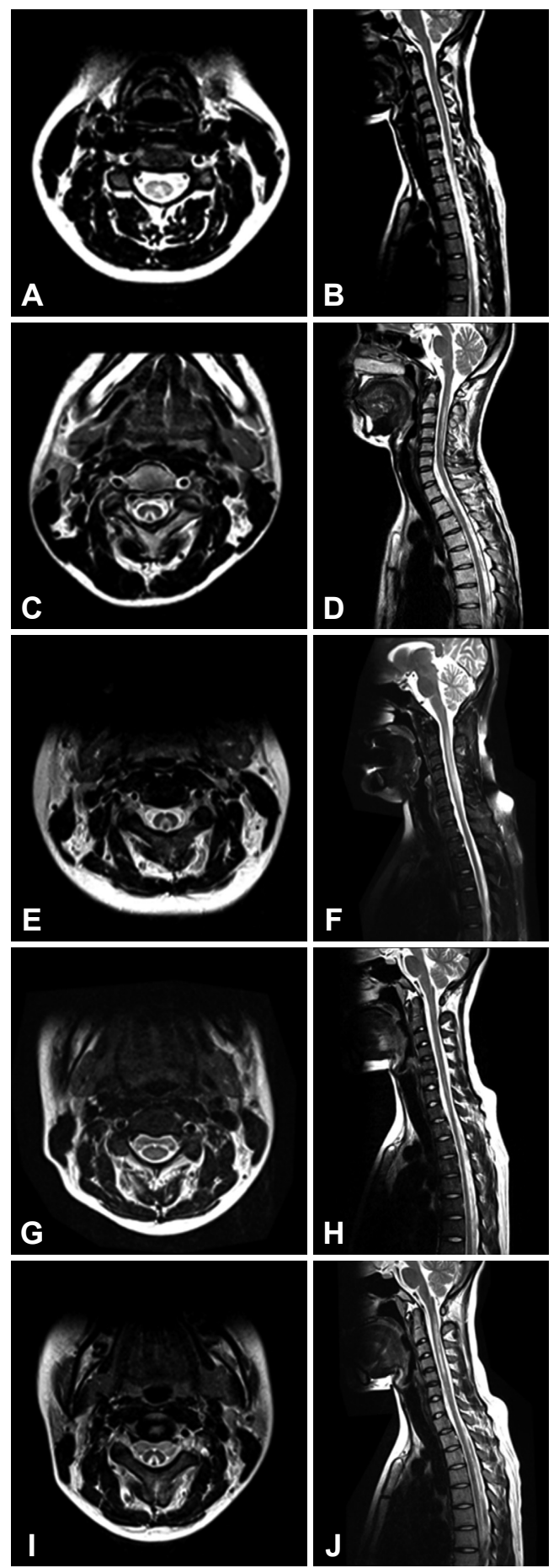

Fig. 1. Findings of axial and sagittal T2-weighted MRI of the cervical spinal cord in all four patients. Patient 1 showed (A) suspicious demyelination within the dorsal columns in an axial view and (B) suspicious demyelination of C2-C5 in a sagittal view. Patient 2 showed (C) demyelination within the dorsal columns in an axial view and (D) demyelination of $\mathrm{C} 1-\mathrm{C} 5$ in a sagittal view. Patient 3 showed (E) demyelination within the dorsal columns in an axial view and (F) demyelination of $\mathrm{C} 1-\mathrm{C} 7$ in a sagittal view. Patient 4 initially showed ( $\mathrm{G}$ and $\mathrm{H}$ ) no abnormal hyperintensities, but 3-month follow-up MRI showed (I) demyelination within the dorsal columns in an axial view and (J) demyelination of $\mathrm{C} 1-\mathrm{C} 6$ in a sagittal view. axonal neuropathy that progressed to motor-dominant polyneuropathy.

$\mathrm{N}_{2} \mathrm{O}$ increases the homocysteine level, which increases the risk of thrombosis. ${ }^{5}$ Patient 4 did not have any symptoms or signs of a pulmonary embolism, but this was detected incidentally in spinal MRI and represents a rare case of incidental pulmonary thromboembolism due to $\mathrm{N}_{2} \mathrm{O}$ abuse.

In conclusion, $\mathrm{N}_{2} \mathrm{O}$ abuse can cause various clinical and neurophysiological manifestations of myeloneuropathy along with psychiatric and medical sequelae. The difficulty of ascertaining the presence of $\mathrm{N}_{2} \mathrm{O}$ abuse and its various clinical features mean that clinicians should not exclude the possibility of $\mathrm{N}_{2} \mathrm{O}$ toxicity in the differential diagnosis when examining patients with ascending paralysis.

\section{Conflicts of Interest}

The authors have no financial conflicts of interest.

\section{REFERENCES}

1. Garakani A, Jaffe RJ, Savla D, Welch AK, Protin CA, Bryson EO, et al. Neurologic, psychiatric, and other medical manifestations of nitrous oxide abuse: a systematic review of the case literature. Am J Addict 2016;25:358-369.

2. Garakani A, Welch AK, Jaffe RJ, Protin CA, McDowell DM. Psychosis and low cyanocobalamin in a patient abusing nitrous oxide and cannabis. Psychosomatics 2014;55:715-719.

3. Lin RJ, Chen HF, Chang YC, Su JJ. Subacute combined degeneration caused by nitrous oxide intoxication: case reports. Acta Neurol Taiwan 2011;20:129-137.

4. Thompson AG, Leite MI, Lunn MP, Bennett DL. Whippits, nitrous oxide and the dangers of legal highs. Pract Neurol 2015;15:207-209.

5. Hathout L, El-Saden S. Nitrous oxide-induced B12 deficiency myelopathy: perspectives on the clinical biochemistry of vitamin B12.J Neurol Sci 2011;301:1-8. 